\title{
Perylene-based All-organic Redox Battery with Excellent Cycling Stability
}

\author{
Adriana Iordache, ${ }^{\dagger,+}$ Virginie Delhorbe, ${ }^{\dagger,+}$ Michel Bardet ${ }^{\dagger, \xi}$ Lionel Dubois, ${ }^{\dagger, \perp}$ Thibaut Gutel ${ }^{\dagger, t^{*}}$ \\ and Lionel Picard ${ }^{\dagger}, t^{*}$
}

†Université Grenoble Alpes, F-38000 Grenoble, France

¥Commissariat à l’énergie atomique et aux énergies alternatives - Direction de la recherche technologique - Laboratoire d'innovation pour les technologies des énergies nouvelles et les nanomatériaux - Département de l'électricité de l'hydrogène pour les transports - Service des composants pour générateurs électrochimiques, 17 Rue des Martyrs, F-38054 Grenoble, France

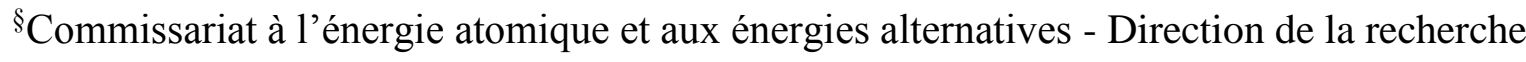
fondamentale - Institut nanosciences et cryogénie - Modélisation et exploration des matériaux, UMR-E CEA-UJF, 17 Rue des Martyrs, F-38054 Grenoble, France

${ }^{\perp}$ Commissariat à l'énergie atomique et aux énergies alternatives - Direction de la recherche fondamentale - Institut nanosciences et cryogénie - Systèmes moléculaires et nanomatériaux pour l’énergie et la santé, UMR-E CEA-UJF, 17 Rue des Martyrs, F-38054 Grenoble, France

Keywords: organic active material; perylene; greener compound; lithium-ion; all-organic battery

Corresponding authors: $\quad \underline{\text { lionel.picard@,cea.fr, thibaut.gutel@,cea.fr }}$ 
Synthesis of PTCLi4 and PTCI: all chemicals were used as received unless otherwise noted. Perylene-3,4,9,10-tetracarboxylic dianhydride (PTCDA, 97\%), lithium hydroxide monohydrate $\left(\mathrm{LiOH} \cdot \mathrm{H}_{2} \mathrm{O}, 98 \%\right)$, m-cresol (99\%), hexamethylenediamine (98\%) and isoquinoline (97\%) were purchased from Aldrich.

The tetra-lithium perylene-3,4,9,10-tetracarboxylate $\left(\mathrm{PTCLi}_{4}\right)$ was synthetized by reacting an excess of $\mathrm{LiOH} \cdot \mathrm{H}_{2} \mathrm{O}$ with the corresponding starting material in water as previously described. ${ }^{1}$ IR, $\mathrm{cm}^{-1}:$ 1595, $1557(\mathrm{C}=\mathrm{O}){ }^{1} \mathrm{H}-\mathrm{NMR}\left(400 \mathrm{Mz}, \mathrm{D}_{2} \mathrm{O}\right) \delta: 8.45(\mathrm{~d}, \mathrm{~J}=8 \mathrm{~Hz}, 4 \mathrm{H}), 7.83(\mathrm{~d}, \mathrm{~J}=8 \mathrm{~Hz}$, 4H). Anal. Calc. \% for C24H8Li4O8: C, 63.76; H, 1.78 Found \%: C, 62.74; H, 2.04.

The poly( $N$ - $n$-hexyl-3,4,9,10-perylene tetracarboxylic)imide (PTCI) was synthesized using the procedure developed by Niu et al. ${ }^{2}$ and heating at $200{ }^{\circ} \mathrm{C}$ for $20 \mathrm{~h}$ all the precursors under controlled atmosphere. The PTCI was washed three times with excess of acetone. IR, $\mathrm{cm}^{-1}: 3100$ $\left(\mathrm{C}-\mathrm{C}_{\mathrm{Ar}}\right), 1687,1640(\mathrm{C}=\mathrm{O})$.

Both synthetized electrode materials are insoluble in conventional solvents, with the exception of PTCLi 4 which is slightly soluble in water. Only ${ }^{1} \mathrm{H}-\mathrm{NMR}$ of the $\mathrm{PTCLi}_{4}$ could be performed.

Fourier transform infrared spectroscopy: FT-IR was performed on powders, using a diamond ATR accessory (Specac) and a Thermo Scientific Nicolet 6700 spectrometer.

Electrode preparation and cell test: coin cells for battery tests were prepared in an Ar filled glove box as follow. The working electrode was prepared by mixing PTCLi4 or PTCI, Super P $^{\circledR}$ (Imerys Graphite \& Carbon Super C65) as conductive additive and polyvinyldene fluoride (PVdF 5130, $12 \%$ solution in N-methyl-2-pyrrolidone or NMP) as the binder in a weight ratio of 40:40:20. The slurry was coated on an aluminum foil current collector, and the resulting positive 
electrode was dried for 48 hours at $60^{\circ} \mathrm{C}$ under vacuum. The typical loading amount of the active material was $0.8-2.2 \mathrm{mg} \mathrm{cm}^{-2}$. The prepared positive electrode and a lithium metal foil negative electrode were assembled in coin cells with a Celgard $\AA 2400$ (Celgard) and Viledon ${ }^{\circledR}$ (Freudenberg) as separators. The all organic battery was assembled using $\mathrm{PTCI} / \mathrm{SP} / \mathrm{PVdF}$ as positive electrode and $\mathrm{PTCLi}_{6} / \mathrm{SP} / \mathrm{PVdF}$ as negative electrode, which was previously lithiated using lithium metal as counter electrode. The electrolyte was a mixture of ethylene carbonate (EC), dimethyl carbonate (DMC), ethyl methyl carbonate (EMC) (EC:DMC:EMC = $1: 1: 1, \mathrm{v} / \mathrm{v})$ and $1 \mathrm{M}$ lithium hexafluorophosphate $\left(\mathrm{LiPF}_{6}, \mathrm{UBE}\right)$. Cyclic voltammetry $(\mathrm{CV}$; scan rate: $0.01 \mathrm{mV}$ $\mathrm{s}^{-1}$ ) and galvanostatic cycling were performed using a multichannel VMP3 potentiostat (Biologic) and an Arbin BT-2000, respectively. The stability of Al foil against lithium metal as counter electrode and using $1 \mathrm{M} \mathrm{LiPF}_{6}$ in $1 \mathrm{M} \mathrm{LiPF} 6$ in 2:1 EC:DMC was reported to take place below $0.5 \mathrm{~V} .{ }^{3}$ With respect to a maximum theoretical capacity of $118 \mathrm{mAh} \mathrm{g}^{-1}$ for $\mathrm{PTCLi}_{4}$ and $113 \mathrm{mAh} \mathrm{g}^{-1}$ for PTCI, and assuming two-electron transfer processes, a $\mathrm{C}$ rate of $1 \mathrm{C}$ is defined as a specific current of $118 \mathrm{~mA} \mathrm{~g}^{-1}$ or $113 \mathrm{~mA} \mathrm{~g}^{-1}$. For the full cell, the positive to negative mass ratio was 0.3 . All potentials are given $v s \mathrm{Li}^{+} / \mathrm{Li}^{0}$.

NMR experiments: all 1D NMR experiments were carried out at room temperature with a BRUKER AVANCE DSX $500 \mathrm{MHz}$ spectrometer, operating at a ${ }^{1} \mathrm{H}$ frequency of $500.13 \mathrm{MHz}$ $\left({ }^{13} \mathrm{C}\right.$ frequency of $\left.125.7 \mathrm{MHz}\right) .1 \mathrm{D}{ }^{13} \mathrm{C}$ spectra were acquired with a $4 \mathrm{~mm}$ Bruker CPMAS probe-head, using the combination of cross-polarization (CP), magic-angle spinning (MAS) of the sample, and high-power proton decoupling methods. The MAS speed was set to 12,000 Hz. ${ }^{1} \mathrm{H}$ radio-frequency field strengths of 70 and $87 \mathrm{kHz}$ were used for proton pulses $\left(90^{\circ}\right.$ pulse duration of $2.8 \mathrm{~ms}$ ) and proton dipolar decoupling, respectively. The ${ }^{13} \mathrm{C}$ radio-frequency field strength was set to match the Hartman-Hahn condition during CP. For each spectrum, 12,000 
transients were accumulated with a CP contact time of $2 \mathrm{~ms}$ and a recycle delay of $5 \mathrm{~s}$. Signals of quaternary carbons were assigned using dipolar dephasing sequence. The chemical shift values were calibrated indirectly with the carbonyl signal of glycine set at $176.03 \mathrm{ppm}$ relative to tetramethylsilane (TMS).

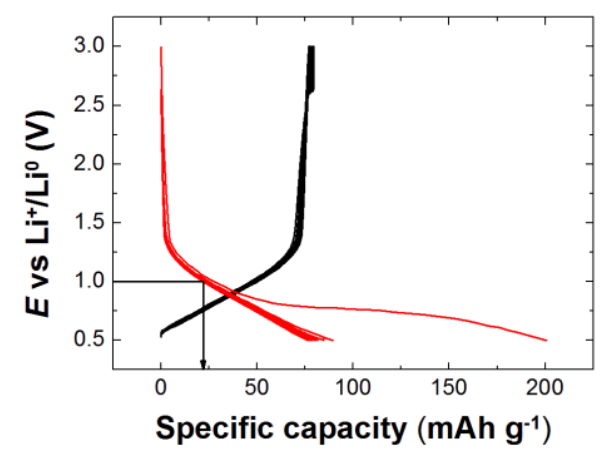

Fig. S1. Discharge (red) /charge (black) cycles of lithium half cells using SP/PVdF $=$ 80:20 (\%wt) as positive electrode, $1 \mathrm{M} \mathrm{LiPF}_{6} / \mathrm{EC}: \mathrm{DMC}: \mathrm{EMC}=1: 1: 1$ (vol) at $\mathrm{C} / 10$ (one $\mathrm{Li}^{+}$exchanged in 10 hours), Li metal as counter electrode, cut-off potential 3 to $0.5 \mathrm{~V}$.

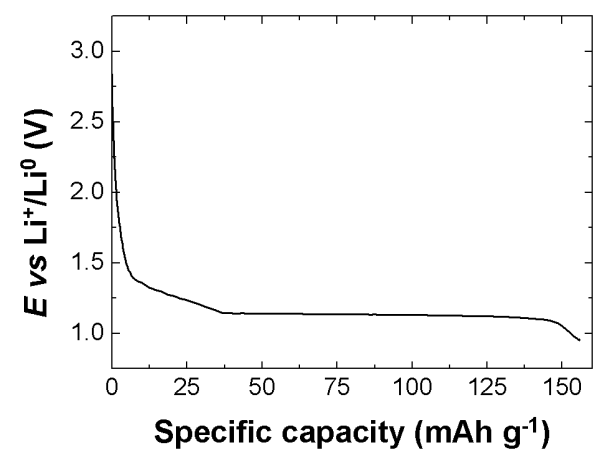

Fig. S2. Electrochemical lithiation of $\mathrm{PTCLi}_{4}$ to $\mathrm{PTCLi}_{6}, \mathrm{PTCLi} / 4 \mathrm{SP} / \mathrm{PVdF}=40 / 40 / 20$ (\% wt) as positive electrode, 1 $\mathrm{MLiPF}_{6} / \mathrm{EC}: \mathrm{DMC}: \mathrm{EMC}=1: 1: 1$ (vol) at $\mathrm{C} / 50$ (one $\mathrm{Li}^{+}$exchanged in 25 hours), Li metal as counter electrode, cutoff potential 3 to $0.95 \mathrm{~V}$. 


\section{REFERENCES}

(1) Fédèle, L.; Sauvage, F.; Bécuwe, M. Hyper-Conjugated Lithium Carboxylate Based on a Perylene Unit for High-Rate Organic Lithium-Ion Batteries. J. Mater. Chem. A 2014, 2, 18225-18228.

(2) Niu, H.; Mu, J.; Zhang, M.; Luo, J.; Luo, P.; Bai, X.; Wang, W. Naphthalene-Containing Polyimides: Synthesis, Characterization and Photovoltaic Properties of Novel Donor-Acceptor Dyes Used in Solar Cell. Trans. Nonferrous Met. Soc. China 2009, 19, s587-s593.

(3) Hamon, Y.; Brousse, T.; Jousse, F.; Topart, P.; Buvat, P.; Schleich, D. M. Aluminum Negative Electrode in Lithium Ion Batteries. J. Power Sources 2001, 97-98, 185-187. 